УДК 621.311 .002

\title{
ФОТОЭЛЕКТРОСТАНЦИИ С ЭЛЕКТРОХИМИЧЕСКИМ И ТЕПЛОВЫМ НАКОПЛЕНИЕМ ЭНЕРГИИ В ИРАКЕ
}

\author{
Лукутин Борис Владимирович1, \\ lukutin48@mail.ru
}

\author{
Аль-Мажди Каррар Хамид 1 , \\ karrar.almussawi.87@gmail.com \\ 1 Национальный исследовательский Томский политехнический университет, \\ Россия, 634050, г. Томск, пр. Ленина, 30.
}

\begin{abstract}
Актуальность. Современные технологии производства энергии с участием возобновляемой энергетики позволяют создать надежные, экономичные и экологически чистые энергоисточники. В статье предложена и обоснована концепция гибридной системы аккумулирования солнечной энергии с использованием фото-электростанции с электрохимическими и тепловыми накопителями генерируемой электроэнергии на примере региона с высоким уровнем солнечной радиации - 2. Багдад (Ирак). Исследования проведены для типичного социального объекта - спортивного зала в Багдаде, нуждающегося в электрической энергии и горячем водоснабжении.

Цель: изучение возможности снижения стоимости фотоэлектрической установки за счет использования комбинированных электрохимических и электротермических аккумуляторов солнечной энергии.

объект: фотоэлектрические системы электроснабжения социально-культурных объектов со значительной долей электрических нагревательных нагрузок на территориях с высоким уровнем инсоляции, например спортивный зал в 2. Багдад.

Методы. Аналитические методы исследования фотоэлектростанций с комбинированным способом аккумулирования солнечной энергии: в электрохимических аккумуляторах и в электротепловых, методы оценки экономических характеристик объектов энергетики, методы компьютерного моделирования.

Результаты. Проведён анализ технико-экономической эффрективности системы электроснабжения с высокой долей тепловых нагрузок, учитьвая непостоянство солнечной радиации по сезонам года, изменения температуры и графиков энергопотребления. Проведено сравнение экономической эффрективности теплового аккумулятора фотоэлектростанции с электрохимическим аккумулированием электроэнергии. Исследования проведены для типичного социального объекта - спортивного зала в Багдаде, с потребностями в электроэнергии для тренажёров, вентиляции, кондиционирования либо отопления, освещения и подогрева воды. Показаны преимущества комбинированных систем аккумулирования электроэнергии фотоэлектростанций объектов с высокой долей электротепловых нагрузок, показаны технико-экономические преимущества использования подобных систем в Ираке: зависимость от иентрализованной электрической сети может быть уменьшена на 80 \% при снижении себестоимости фотоэлектричества более чем в 2 раза относительно сетевого тарифа.
\end{abstract}

\section{Ключевые слова:}

Возобновляемая энергия, солнечная радиация, фотоэлектростанция,

электрохимические и электротермические накопители электроэнергии, компьютерное моделирование.

\section{Введение}

Глобальное потепление стало одной из самых актуальных проблем в современном мире. Причиной является быстрый рост населения планеты, вызвавший увеличение глобального спроса на энергию. Использование углеводородных энергоресурсов для удовлетворения этого спроса является основной причиной глобального потепления [1]. Кроме того, сжигание углеводородного топлива оказывает серьезное негативное влияние на окружающую среду [2]. В настоящее время ископаемое топливо потребляется со скоростью большей, чем скорость его образования в недрах Земли под воздействием тепла и давления и в будущем оно полностью исчезнет. Потребление энергии во всем мире составляет около 10 млрд т условного топлива в год. Доля нефти в общем потреблении составляет $40 \%$, а доля газа - 50 \% [3]. Согласно прогнозным научным исследованиям, концентрация углекислого газа увеличится на 75-350 \% к 2100 г. по сравнению с уровнем 1850 г., что приведет к увеличению парникового эффекта в атмосфере Земли [4]. Воздействия энергетической отрасли на окружающую среду могут быть намного меньше, если использовать возобновляемые источники энергии [5]. Для этого энергетический сектор должен приложить серьёзные усилия в области возобновляемых источников энергии в дополнение к мерам по улучшению традиционной энергетики. Возобновляемые источники энергии, такие как энергия ветра, солнечная энергия, геотермальная энергия и др., могут в значительной степени заменить существующие топливные источники первичной энергии и усовершенствовать процессы преобразования, транспортировки и распределения электроэнергии. Солнечная энергия является одним из наиболее важных источников экологически чистой энергии в мире, который можно использовать для удовлетворения глобальных потребностей в энергии, необходимых для повседневных нужд в промышленности и быту. Кроме электроэнергии, существует большой потенциал использования солнечной энергии для удовлетворения потребностей в тепле на фабриках, фермах, в зданиях, в развлекательных заведениях и т. д. [6-8].

Тепловое воздействие солнечной радиации широко применяется для обогрева зданий и горячего водо- 
снабжения путем использования солнечных коллекторов. Комплексная эффективность солнечного коллектора достигает 51-61 \% без концентратора и с концентратором солнечного излучения соответственно [9]. Солнечные коллекторы являются основой солнечных теплоэнергетических систем. Горячая вода является вторым по величине потребляемым энергоресурсом в мире. Сегодня солнечные водонагревательные системы используются в домах на одну семью, многоквартирных домах, школах, автомойках, больницах, ресторанах, фермерских хозяйствах, развлекательных комплексах и в различных отраслях промышленности [10]. Эффективность солнечного коллектора зависит от интенсивности солнечного излучения и от разницы температур окружающего воздуха, коллектора и теплоносителя - воды [11]. Максимальная температура воды на выходе $-55^{\circ} \mathrm{C}$ - была зарегистрирована в плоском коллекторе при общих потерях тепла 3,2 МДж/день, что эквивалентно 16,4 \% энергии, собранной плоским коллектором [12].

Большое внимание уделяется повышению эффективности систем возобновляемой энергетики, участвующих в энергообеспечении различных объектов, для сокращения токсичных выбросов и улучшения экономических характеристик [13-15].

Возобновляемая энергия, в первую очередь солнечная, перспективна для использования в системах электроснабжения, особенно в случаях их удаленности от централизованных энергосистем или высокой стоимости предлагаемой электроэнергии. Однако высокая стоимость энергетического оборудования для фотоэлектрических станций всё ещё является ограничивающим фактором для их широкого практического применения. Снижение стоимости является основным критерием оптимизации нестационарных процессов преобразования энергии в фотоэлектрических системах и, соответственно, характеристик их энергетического оборудования. В частности, известна проблема существенного несоответствия между графиком инсоляции и энергопотребления различных объектов. Для координации энергетического баланса фотоэлектрической системы широко используются электрохимические батареи, обеспечивающие аккумулирование электроэнергии для надёжного электроснабжения потребителей. Однако аккумуляторы критичны к температуре и имеют ограниченный срок службы и высокую стоимость.

Аккумулирование электрической энергии фотоэлектростанций может быть реализовано не только в электрохимических батареях, но и в более дешёвых водонагревательных установках, что позволит снизить стоимость фотоэлектрической установки за счет уменьшения емкости аккумуляторов и обеспечить горячей водой потребителя. Существует большое количество солнечных водонагревателей прямого действия, характеризующихся простотой конструкцией и низкой стоимостью. Стоимость единицы площади коллектора разных конструкций варьируется в зависимости от конструкции и технических характеристик. Самые простые солнечные коллекторы стоят 2,3 тыс. p./м². Эти коллекторы имеют коэффициент полезного действия около 0,19. Цена более совершенных вакуумных трубчатых коллекторов превышает 25 тыс. p./ м $^{2}$ что дороже удельной стоимости фотоэлектрических панелей. Эффективность этих комплексов составляет 0,51-0,57 [16]. Недостатком солнечных водонагревателей является зависимость их производительности от солнечных и погодных условий

Эффективность фотоэлектрического преобразования в широком диапазоне изменений энергии солнечного излучения практически не изменяется, расширяя возможности фотоэлектрических электростанций, включая горячее водоснабжение с электронагревательными элементами.

Электрические нагрузки можно разделить на несколько категорий, включая жилые, промышленные, коммерческие и правительственные. Эти компоненты различаются в электрической системе в зависимости от экономической, политической, социальной ситуации в стране и т. д. Фактор разнообразия электрических нагрузок изучался в иракской системе распределения электроэнергии. Исследование показывает, что бытовые и промышленные электрические нагрузки росли со скоростью, превышающей средние значения [17]. Жилые нагрузки представляют самые большие компоненты в иракских электрических системах. Бытовые электрические нагрузки состоят из множества электроприёмников: бытовой техники, освещения, отопления помещений, охлаждения и нагрева воды. Исследование показало, что на нагревание воды расходуется больше всего электроэнергии - до 32,29 \% [18].

Аккумулирование тепловой энергии снижает расходы на электроэнергию, позволяя избегать повышенных тарифов в часы пик. Тепловая энергия может быть собрана, когда это возможно, и использоваться при необходимости даже в другое время года. Например, тепло может собираться от солнечных коллекторов в жаркие месяцы, чтобы при необходимости использовать его для обогрева помещений, в том числе в зимние месяцы. Аккумулирование энергии выгодно для пользователей, которые могут гибко следовать спросу и предложению на энергоресурсы [19].

Учитывая дефицит энергосистемы Ирака, восполняемый за счёт импорта около $22 \%$ электроэнергии из Ирана (на фоне санкций со стороны США к участникам сотрудничества с Ираном), весьма актуальной проблемой энергетики Ирака является снижение нагрузки энергосистемы, в том числе за счёт ввода генерирующих мощностей возобновляемой энергетики, в первую очередь солнечной [20].

\section{Описание системы и математическая модель}

Обширная площадь и малая плотность населения Ирака при высоком потенциале солнечной энергии определяют перспективность использования фотоэлектрических станций. Территория Ирака находится под воздействием энергии солнечного излучения, получая около 2000 кВт*ч/ ${ }^{2} /$ год, что определяет актуальность использования технологий солнечной энергетики для поддержки экономики страны путём сокращения электропотребления в иракской национальной электрической сети [21]. Ирак считается вто- 
рой страной в мире по интенсивности энергии солнечного излучения. На основе построенной карты распределения инсоляции по территории Ирака определены потенциальные районы для создания крупномасштабных солнечных электростанций и показано, что Ирак относится к странам, наиболее подходящим для использования солнечной энергии [22].

Выбор оборудования для децентрализованных фотоэлектрических станций определяется инсоляцией и графиком потребления электроэнергии. Схема пред- лагаемой независимой гибридной фотоэлектрической установки с резервированием от дополнительного источника энергии - дизельного генератора - или централизованной сети представлена на рис. 1. Схема отличается от обычной фотоэлектрической установки с электрохимическим аккумулятором электроэнергии и резервным дизель-генератором наличием тепловых нагрузок, которые питаются непосредственно от массива фотоэлектрических модулей через специальный тепловой контроллер.

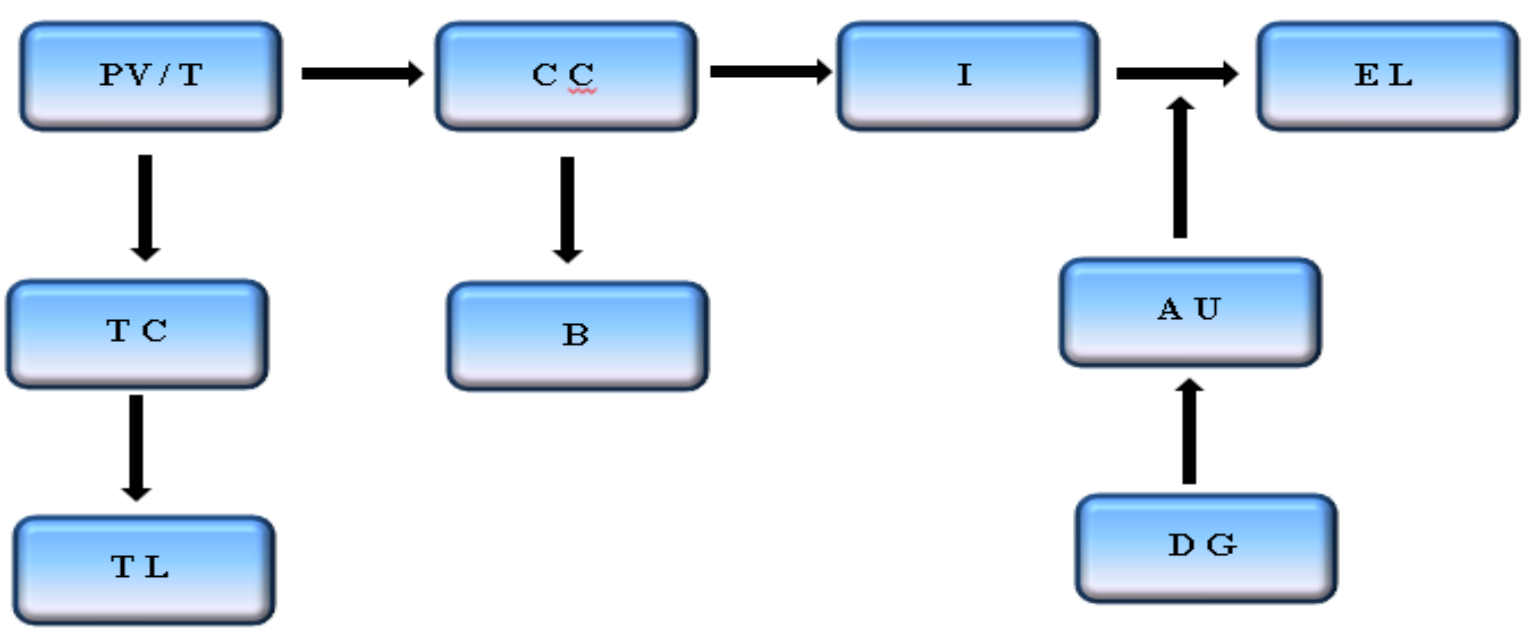

Рис. 1. Структурная схема фотоэлектрической системы с электрохимическим и электротепловым аккумуляторами Fig. 1. Block diagram of a photovoltaic system with electrochemical and electro thermal batteries

На рис. 1 приняты обозначения: PV/T - массив фотоэлектрических модулей; TL - тепловая нагрузка-аккумулятор; TC - тепловой контроллер; В - батарея электрохимических аккумуляторов; СС - контроллер заряда аккумуляторной батареи; I - инвертор; DG - дизельный генератор или другой энергоисточник; $\mathrm{AU}$ - блок автоматического включения резерва; EL - электрическая нагрузка.
Район исследования - столица Ирака, г. Багдад, находится на высоте 40 м над уровнем моря. Город расположен на $33^{\circ} 20^{\prime} 19$ "северной широты и $44^{\circ}$ 23'38" восточной долготы. Удельная суточная инсоляция в районе Багдада по месяцам года для поверхности с оптимальным углом наклона относительно горизонтальной поверхности показана в табл. 1.

Таблица 1. Солнечная радиация в районе объекта энергообеспечения

Table 1. Solar radiation in the area of the energy supply facility

\begin{tabular}{|c|c|c|c|c|c|c|c|c|c|c|c|c|}
\hline $\begin{array}{l}\text { Месяц } \\
\text { Month }\end{array}$ & $\begin{array}{c}\text { Янв } \\
\text { Jan }\end{array}$ & $\begin{array}{l}\text { Фев } \\
\text { Feb }\end{array}$ & $\begin{array}{l}\text { Mapт } \\
\text { Mar }\end{array}$ & $\begin{array}{l}\text { Апр } \\
\text { Арr }\end{array}$ & $\begin{array}{l}\text { Май } \\
\text { Мау }\end{array}$ & $\begin{array}{c}\text { Июн } \\
\text { Jun }\end{array}$ & $\begin{array}{c}\text { Июль } \\
\text { Jul }\end{array}$ & $\begin{array}{l}\text { Авг } \\
\text { Aug }\end{array}$ & $\begin{array}{l}\text { Сент } \\
\text { Sep }\end{array}$ & $\begin{array}{l}\text { Окт } \\
\text { Oct }\end{array}$ & $\begin{array}{l}\text { Нояб } \\
\text { Nov }\end{array}$ & $\begin{array}{l}\text { Дек } \\
\text { Dес }\end{array}$ \\
\hline $\begin{array}{l}\text { Солнечная радиация, } \\
\mathrm{KBT}^{*} \mathrm{~m} / \mathrm{m}^{2} / \text { день } \\
\text { Solar radiation, } \\
\mathrm{kWh} / \mathrm{m}^{2} / \text { day }\end{array}$ & 3 & 3,8 & 4,8 & 5,7 & 6,5 & 7,3 & 7,2 & 6,6 & 5,7 & 4,4 & 3,3 & 2,7 \\
\hline
\end{tabular}

В качестве примера объекта энергообеспечения выбран социальный объект - спортивный зал. Зал имеет площадь $200 \mathrm{~m}^{2}$ и рассчитан на 30 посетителей в день. Время работы зала - с 10 до 22 часов. Объект нуждается в электрической и тепловой энергии. Учитывая высокий энергетический потенциал солнечного излучения, рассмотрим возможности фотоэлектростанции для энергообеспечения спортивного зала. Кроме электрической энергии, тренажёрный зал нуждается в горячем водоснабжении. Энергетические затраты на подогрев воды могут быть подсчитаны по формуле

$$
P t=m C w(Q 2-Q 1)
$$

где $t$ - время нагрева воды [c]; $P$ - мощность нагревательного элемента [кВТ]; $m$ - масса воды [кг]; $C w=4,2$ кДж/кг град - удельная теплоёмкость воды; $Q 2$ и $Q 1$ - конечная и начальная температура воды.

В соответствии с нормативами расход воды в душевых спортивных залов - от 15 до 30 л на человека $[23,24]$. Примем среднее значение - 22 л горячей воды, что суммарно для 30 посетителей рассматриваемого объекта составит 660 л/день. Энергия, необходимая для нагрева 660 л воды до температуры 65 градусов, равна:

$W г \mathrm{~B}=660 * 4,2 *(65-13)=144$ кВт·ч. (летом и весной $)$,

$W_{\Gamma \mathrm{B}}=660 * 4,2 *(65-3,5)=170$ кВТ·ч. (зимой и осенью). 
Следовательно, средняя мощность электронагревательных приборов, при условии нагревания за световой день (весна-лето 13 часов, осень-зима 10 часов), равна, соответственно 11 и 17 кВт. Ис- ходная температура воды принята летом $13^{\circ}$, зимой $-3,5^{\circ}$. Мощности и время работы электроприёмников спортивного зала по сезонам года приведены в табл. 2.

Таблица 2. Энергетические характеристики электроприёмников по сезонам

Table 2. Energy characteristics of electrical receivers by season

\begin{tabular}{|c|c|c|c|c|c|c|c|c|}
\hline \multirow{3}{*}{$\begin{array}{l}\text { Электроприёмники } \\
\text { Electrical receivers }\end{array}$} & \multicolumn{8}{|c|}{$\begin{array}{l}\text { Мощность и время работы электроприёмников для средних суток по сезонам года } \\
\text { Power and operating time of electrical devices for typical days by seasons of the year }\end{array}$} \\
\hline & \multicolumn{2}{|c|}{ Зима/Winter } & \multicolumn{2}{|c|}{ Весна/Spring } & \multicolumn{2}{|c|}{ Лето/Summer } & \multicolumn{2}{|c|}{ Осень/Autumn } \\
\hline & \begin{tabular}{|c|} 
Мощность, $\mathrm{kBT}$ \\
Power, $\mathrm{kW}$
\end{tabular} & $\begin{array}{c}\text { Bремя, ч } \\
\text { Time, hour }\end{array}$ & $\begin{array}{c}\text { Мощность, кBт } \\
\text { Power, } \mathrm{kW}\end{array}$ & \begin{tabular}{|l} 
Время, ч \\
Time, hour
\end{tabular} & $\begin{array}{l}\text { Мощность, кBT } \\
\text { Power, } \mathrm{kW}\end{array}$ & $\begin{array}{c}\text { Время, ч } \\
\text { Time, hour }\end{array}$ & $\begin{array}{c}\text { Мощность, } \mathrm{kBT} \\
\text { Power, } \mathrm{kW}\end{array}$ & $\begin{array}{c}\text { Время, ч } \\
\text { Time, hour }\end{array}$ \\
\hline $\begin{array}{l}\text { Освещение зала } \\
\text { Hall lighting }\end{array}$ & 4 & 12 & 4 & 12 & 4 & 12 & 4 & 12 \\
\hline $\begin{array}{l}\text { Tренажёр } \\
\text { Fitness machine }\end{array}$ & 3 & 12 & 3 & 12 & 3 & 12 & 3 & 12 \\
\hline $\begin{array}{l}\text { Водоснабжение } \\
\text { Water supply }\end{array}$ & 0,5 & 3 & 0,5 & 4 & 0,5 & 6 & 0,5 & 3 \\
\hline Сауна/Sauna & 2,6 & 5 & 2,6 & 5 & 2,6 & 5 & 2,6 & 5 \\
\hline $\begin{array}{l}\text { Отопление помещений } \\
\text { Space heating }\end{array}$ & 20 & 12 & 0 & 0 & 0 & 0 & 20 & 8 \\
\hline $\begin{array}{l}\text { Кондиционер } \\
\text { Air-condition }\end{array}$ & 0 & 0 & 6 & 6 & 6 & 12 & 0 & 0 \\
\hline $\begin{array}{l}\text { Oхранная сигнализация } \\
\text { Security alarm }\end{array}$ & 0,16 & 12 & 0,16 & 12 & 0,16 & 12 & 0,16 & 12 \\
\hline $\begin{array}{l}\text { Стиральная машина } \\
\text { Washing machine }\end{array}$ & 0,5 & 4 & 0,5 & 4 & 0,5 & 4 & 0,5 & 4 \\
\hline $\begin{array}{l}\text { Горячее водоснабжение } \\
\text { Water heating }\end{array}$ & 17 & 10 & 11 & 13 & 11 & 13 & 17 & 10 \\
\hline $\begin{array}{l}\text { Освещение автостоянки } \\
\text { Car park lighting }\end{array}$ & 1 & 14 & 1 & 12 & 1 & 10 & 1 & 12 \\
\hline $\begin{array}{l}\text { Вентиляция } \\
\text { Ventilation }\end{array}$ & 0,6 & 12 & 0,6 & 12 & 0,6 & 12 & 0,6 & 12 \\
\hline
\end{tabular}

Учитывая значительную долю электронагревательного оборудования, суммарное суточное электропотребление для рассматриваемого объекта определится как:

$$
W_{\mathrm{H}}=W_{\ni}+W_{\text {гв}},
$$

где $W \ni$ - электроэнергия, потребляемая электрическими нагрузками; Wгв - электроэнергия, потребляемая водонагревателем.

По сезонам года величина суммарного электропотребления $\mathrm{WH}_{\mathrm{H}}$ изменяется в широких пределах: от 302 кВТ*ч в день весной и 337 кВт*ч летом до 452 кВт*ч осенью и 534 кВт*ч зимой.

Следует отметить, что значительная часть электроэнергии расходуется на подогрев воды: весной и летом 144 кВт*ч, осенью и зимой 170 кВт*ч. Электрическая мощность, используемая для подогрева воды (при условии её нагревания за усреднённый световой день) осенью-зимой, летом-весной равна 17 и 11 кВт, соответственно.

Энергия, потребляемая электрическими нагрузками в сутки по сезонам, равна: весной - 152 кВтч, летом - 187 кВтч, осенью - 267 кВтч, зимой - 349 кВтч.

Общий энергетический баланс нагрузок объекта энергоснабжения: суммарная энергия $W_{\mathrm{H}}$, энергия электрических нагрузок Wэ и энергия электронагревателя $W$ гв, для средних суток по сезонам года приведен в табл. 3.

Эти объёмы электроэнергии должны ежедневно генерироваться фотоэлектростанцией или другим энергоисточником, причём для фотоэлектростанции необходимое количество этой энергии должно поступать к электроприёмникам через системы накопления ввиду неполного совпадения временных интервалов инсоляции и электропотребления.

Таблица 3. Энергетический баланс тепловых и электрических нагрузок

Table 3. Energy balance of thermal and electrical loads

\begin{tabular}{|c|c|c|c|c|}
\hline \multirow{2}{*}{$\begin{array}{c}\text { Общая энергия } \\
\text { в течение дня, кВтч } \\
\text { Total energy during } \\
\text { the day, kWh }\end{array}$} & \multicolumn{4}{|c|}{ Сезон/Season } \\
\hline & $\begin{array}{c}\text { Зима } \\
\text { Winter }\end{array}$ & $\begin{array}{l}\text { весна } \\
\text { Spring }\end{array}$ & $\begin{array}{c}\text { Лето } \\
\text { Summer }\end{array}$ & $\begin{array}{c}\text { осень } \\
\text { Autumn }\end{array}$ \\
\hline $\mathrm{WH}_{\mathrm{H}}$ & 534 & 302 & 337 & 452 \\
\hline Wэ & 364 & 158 & 193 & 282 \\
\hline Wгв & 170 & 144 & 144 & 170 \\
\hline
\end{tabular}

Для моделирования фотоэлектростанции воспользуемся программным комплексом [25]. Вид диалогового окна для выбранного района - г. Багдад - приведён на рис. 2.

Среднесуточная потенциальная генерация электроэнергии фотоэлектростанции, состоящей из 300 фотоэлектрических модулей НH-MONO-200W, изменяется от 236 кВт*ч/сутки в декабре до 393 кВт*ч/сутки в июне. Суммарное годовое производство электроэнергии может достигать 117286,80 кВт*ч.

В результате исследований на компьютерной модели установлено, что электроэнергии фотоэлектростанции с используемым типом и количеством фотоэлектрических панелей достаточно для полного обеспечения спортивного зала в весенне-летний сезон. В осенне-зимний период фотоэлектрическая генерация покрывает не более половины необходимой электроэнергии. 


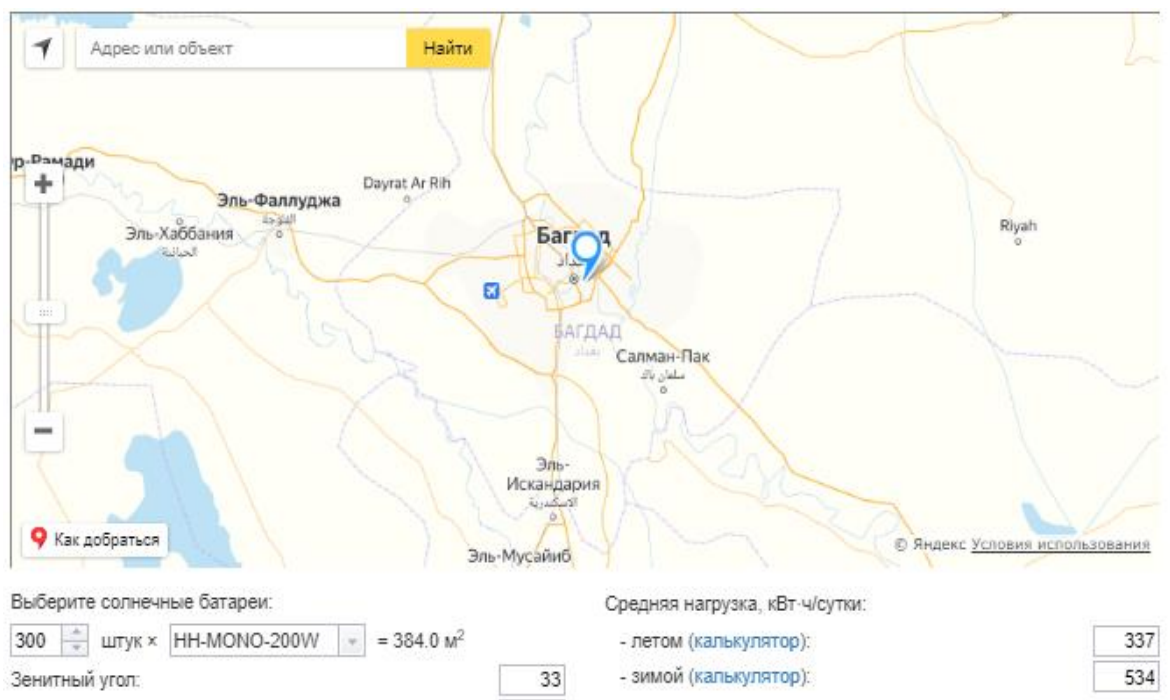

Pис. 2. Данные для моделирования фотоэлектростанциии

Fig 2. Initial data for modeling a photovoltaic plant

Суточные зависимости энергии фотоэлектростанции $W \phi$ и энергии электрической нагрузки объекта за усреднённый рабочий день, включающей электрические Wэ и электронагревательные $W_{г в}$ электроприёмники, по сезонам года приведены на рис. 3. По характеру распределения указанных вели- чин в течение суток заметно несоответствие периода инсоляции временному интервалу электропотребления. Для устранения этого противоречия, при условии снижения нагрузки на централизованную электрическую сеть, необходимо использование накопителей энергии.

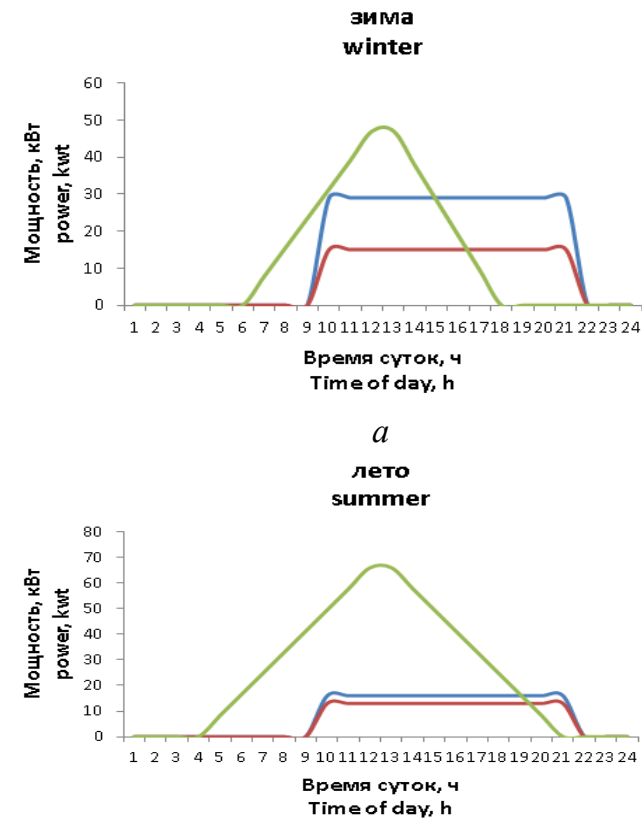

$\sigma$
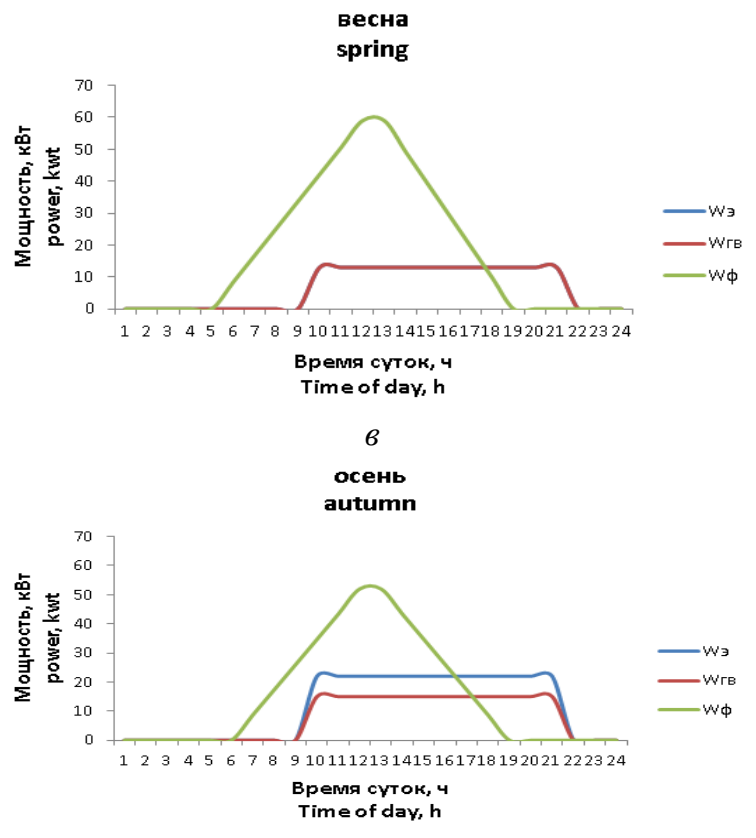

2

Pис. 3. а-г) Временные зависимости средней энергии электрических нагрузок Wэ, электронагревательных нагрузок Wгв и энергии генерачии фотоэлектростанции $W \phi$ в течение средних суток сезонов года

Fig. 3. a-2) Time dependences of the average energy of electrical loads $W_{3}$, electric heating loads W2в and the generation energy of the photoelectric power plant $W \phi$ during the average day of the seasons

Исходя из анализа представленных на рис. 3, $a-2$ временных зависимостей энергии солнечного излучения и электропотребления, получается, что в весеннелетний сезон от 25 до $33 \%$ рабочего времени электропитание объекта осуществляется от аккумуляторов либо от дополнительного энергоисточника.
В осенне-зимний сезон этот период увеличивается до 40-50 \% рабочего времени.

Энергетический баланс фотоэлектрической системы электроснабжения объекта с аккумуляторным накопителем электроэнергии за рабочий день может быть представлен формулой: 


$$
W ф-W_{\ni}-W_{г в}-+W a-+W д=0,
$$

где $W \phi, W \ni, W г в, W a, W д-$ соответственно, энергия фотоэлектрической генерации за световой день, энергия электропотребления за рабочее время, расход электроэнергии на горячее водоснабжение, энергия заряда или разряда аккумулятора (ночным электропотреблением можно пренебречь), энергия дополнительного источника (сеть).

\section{Результаты исследования}

Оценка энергетических характеристик накопителя электрической энергии, необходимого для использования в фотоэлектростанции с гибридным электрохимическим и электротепловым аккумулятором и только электрохимическим, выполнена моделированием энергетических характеристик рассматриваемого энергетического комплекса в программном комплексе [25].

В результате моделирования установлено, что для полного энергообеспечения объекта электроэнергией от фотоэлектростанции в течение средних суток весенне-летнего сезона необходимы электрохимические аккумуляторы ёмкостью 6000 Ач. Предельная глубина разряда аккумуляторов не превышает при этом $30 \%$. В осенне-зимний сезон энергии этих аккумуляторов хватит только на 2 часа автономной работы, что требует использования дополнительного энергоисточника.

Вариант с гибридным аккумулированием фотоэлектричества предусматривает использование электрохимических аккумуляторов только для питания электрических нагрузок. Соответственно, аккумуляторы ёмкостью 3000 Ач обеспечат независимое электропитание потребителей в течение характерных суток весенне-летнего сезона с аналогичной глубиной разряда $30 \%$. В осенне-зимний сезон аккумуляторы смогут независимо питать электрические нагрузки в течение 2 часов.

Таким образом, для рассматриваемого примера применение гибридной аккумулирующей системы позволяет в два раза уменьшить необходимый запас энергии электрохимических аккумуляторов.

Данные суточных энергетических характеристик системы электроснабжения рассматриваемого объекта и его взаимодействие с дополнительным энерго- источником Wд приведены в табл. 4. Отрицательные значения энергии дополнительного источника свидетельствуют о возможности её передачи в централизованную энергосистему.

Таблица 4. Энергетические характеристики гибридной системы (усреднённый день для каждого сезона)

Table 4. Energy characteristics of the hybrid system (typical day for each season)

\begin{tabular}{|c|c|c|c|c|}
\hline \multirow{2}{*}{$\begin{array}{c}\text { Энергия в течение дня, } \\
\text { кВт*ч }^{*} \text {. } \\
\text { Total energy during } \\
\text { the day, kWh }\end{array}$} & \multicolumn{4}{|c|}{ Сезон/Season } \\
\hline & $\begin{array}{c}\text { Зима } \\
\text { Winter }\end{array}$ & $\begin{array}{l}\text { Весна } \\
\text { Spring }\end{array}$ & $\begin{array}{c}\text { Лето } \\
\text { Summer }\end{array}$ & $\begin{array}{c}\text { Осень } \\
\text { Autumn }\end{array}$ \\
\hline $\mathrm{WH}$ & 534 & 302 & 337 & 452 \\
\hline $\mathrm{W \phi}$ & 270 & 336 & 381 & 298 \\
\hline Wд & 264 & -34 & -44 & 154 \\
\hline Wгв & 170 & 144 & 144 & 170 \\
\hline
\end{tabular}

Удельная стоимость ёмкости свинцово-кислотных аккумуляторов $0,06 \$ / \mathrm{BT}^{*}$ ч [26]. Тогда стоимость аккумуляторов ёмкостью 6000 Ач равна 4320 \$. Цена накопительных электрических водонагревателей объёмом сотни литров для большинства производителей колеблется от 1,2 до 2,2 \$ за единицу объёма [16], что для суточного объёма нагреваемой воды 660 л составит в среднем около 1100 \$. Таким образом, гибридная система аккумулирования электроэнергии стоит 3260 \$ против 4320 \$ за электрохимические аккумуляторы с теми же энергетическими возможностями. Для оценки экономических характеристик рассматриваемого энергетического комплекса приведём стоимостные характеристики основного энергетического оборудования, представленные в табл. 5 (звёздочкой отмечено количество единиц оборудования для варианта с электрохимическими аккумуляторами).

Срок службы фотоэлектрических модулей превышает 20 лет, нормативный коэффициент рентабельности $\mathrm{PH}_{\mathrm{H}} 0,05$. Срок службы аккумуляторных батарей серий DTM составляет не менее 12 лет, инвертора и контроллеров - более 10 лет. Соответственно, за 20 лет эксплуатации количество единиц оборудования, кроме фотоэлектрических модулей, следует увеличить в два раза. Эксплуатационные затраты примем 100000 р./год.

Таблица 5. Стоимость энергетического оборудования автономной гибридной фотоэлектростанции

Table 5. Cost of power equipment of an autonomous hybrid photo-power plant

\begin{tabular}{|c|c|c|c|}
\hline $\begin{array}{c}\text { Номенклатура товара } \\
\text { Item nomenclature }\end{array}$ & $\begin{array}{l}\text { Кол-во, шт. } \\
\text { Quantity, pcs. }\end{array}$ & $\begin{array}{c}\text { Цена за шт., p. } \\
\text { Price per piece, rub. }\end{array}$ & $\begin{array}{l}\text { Сумма, p. } \\
\text { Amount, rub. }\end{array}$ \\
\hline $\begin{array}{l}\text { Фотопанели НH-MONO 200W } \\
\text { Photo panels HH-MONO 200W }\end{array}$ & 300 & 11000 & 3300000 \\
\hline $\begin{array}{l}\text { Тепловой контроллер } \\
\text { Thermal controller }\end{array}$ & 2 & 30000 & 60000 \\
\hline $\begin{array}{l}\text { АКБ - Delta DTM } 12200 \mathrm{~L} \\
\text { Battery - Delta DTM } 12200 \mathrm{~L}\end{array}$ & $16 / 32 *$ & 35500 & $568000 / 1136000 *$ \\
\hline $\begin{array}{l}\text { Инвертор МАР-HYBRID-48-20 } \\
\text { Inverter MAP-HYBRID-48-20 }\end{array}$ & $2 / 4 *$ & 195900 & $391800 / 783600 *$ \\
\hline $\begin{array}{l}\text { Итого оборудование } \\
\text { Total equipment }\end{array}$ & - & - & $4318000 / 5279000 *$ \\
\hline $\begin{array}{l}\text { Строительно-монтажные работы } \\
\text { (20\% от стоимости) } \\
\text { Construction and installation works } \\
(20 \% \text { of the cost) }\end{array}$ & - & - & $863000 / 1050800 *$ \\
\hline Итого/Total & - & - & $5181000 / 6329800^{*}$ \\
\hline
\end{tabular}


Тогда себестоимость электроэнергии фотоэлектростанции с гибридной системой аккумулирования составит:

$$
\text { Сэл }=\{(0,05 * 5181000)+100000\} / 117286=3,1 \text { р./кВт } * \text { ч. }
$$

Себестоимость электроэнергии варианта энергетического комплекса только с электрохимическим аккумулированием электроэнергии ФЭС составит:

$$
\text { Сэл }=\{(0,05 * 6329800)+100000\} / 117286=3,5 \text { р./кВт*ч. }
$$

По данным [27] средний тариф на электроэнергию в Ираке равен 0,1 Евро, что по курсу соответствует 7,68 р./кВт*ч. Расчётная себестоимость электроэнергии фотоэлектростанции более чем в два раза ниже тарифа на электроэнергию от централизованной энергосистемы. Сравнивая себестоимость электроэнергии, производимой двумя вариантами фотоэлектрического энергокомплекса, видно, что вариант с гибридной системой аккумулирования фотоэлектричества экономически предпочтительнее.

Годовые финансовые затраты на энергообеспечение спортивного зала, потребляющего порядка 150 тыс. кВт*ч электроэнергии, при питании от централизованной электрической сети, составляют 1150 тыс. р. Использование фотоэлектростанции позволяет производить около 120 тыс. кВт*ч электроэнергии, сокращая потребление из электрической сети до 30 тыс. кВт*ч. При этом расходы на электроэнергию сокращаются до 600 или 650 тыс. р. в год для энергетического комплекса с гибридной системой аккумулирования фотоэлектричества или только с электрохимической, соответственно. Таким образом, годовая экономия финансовых средств на электроэнергию достигает для рассмотренных вариантов фотоэнергетического комплекса 500-550 тыс. р. в год, что обеспечивает окупаемость оборудования фотоэлектростанции (стоимость оборудования: 5181000 или 6329800 р. для рассмотренных вариантов) за 10-12 лет при расчётном сроке эксплуатации 20 лет.

Следует отметить, что цена на возобновляемую электроэнергию будет уменьшаться и в дальнейшем из-за снижения стоимости оборудования для возобновляемой энергетики, что будет способствовать повышению экономической эффективность подобных проектов.

\section{Заключение}

Показана перспективность использования фотоэнергетики для снижения нагрузки на энергодефицитную энергосистему Ирака и расходов на электроэнергию для конкретных потребителей. На примере

\section{СПИСОК ЛИТЕРАТУРЫ}

1. BP Statistical review of world energy 2018. URL: https://bp.com/content/dam/bp/business-sites/en/global/ corporate/pdfs/energy-economics/statistical-review/bp-statsreview-2018-full-report.pdf (дата обращения: 15.11.2020).

2. Sawe Y., Gopta S.C., Bohra A.V. Review of hybrid renewable energy systems with comparative analysis of off-grid system // Renewable and Sustainable Energy Reviews. - 2018. - V. 81 (2). P. 2217-2235.

3. Key world energy statistics. International Energy Agency. 2010. URL: http://www.iea.org (дата обращения: 15.11.2020). социального объекта - спортивного зала - проиллюстрированы возможности использования солнечной энергии для обеспечения объекта более дешёвой электроэнергией и горячей водой с минимальной зависимостью от централизованной сети.

Основные результаты исследования:

1. Использование систем накопления солнечной энергии с электрохимическими и тепловыми аккумуляторами позволяет снизить необходимый запас энергии электрохимических батарей за счет выделения энергии, потребляемой тепловыми нагрузками. Для рассматриваемого примера ёмкость аккумуляторных батарей удалось уменьшить в 2 раза. Использование части электроэнергии фотоэлектрических модулей для нагревания воды не позволяет осуществлять обратное преобразование низкопотенциальной горячей воды в электричество, но потребности объекта в горячем водоснабжении нивелируют этот недостаток.

2. Эффективность непосредственного преобразования электроэнергии массива фотоэлектрических модулей в тепло выше, чем эффективность её теплового преобразования через промежуточное звено - электрохимический аккумулятор со своим коэффициентом полезного действия.

3. Удельная стоимость утилизации электроэнергии в виде тепловой энергии меньше стоимости аккумулирования в электрохимических аккумуляторах. Собственно, бак- утилизатор является электронагревательной нагрузкой, обеспечивающей горячее водоснабжение в любом варианте энергетического комплекса.

4. Работа показывает снижение стоимости гибридной (электротепловой совместно с электрохимической) системы аккумулирования электроэнергии по сравнению с электрохимическими батареями с тем же запасом энергии и, следовательно, более низкую стоимость электроэнергии, производимой фотоэлектрической станцией. Для рассматриваемого примера себестоимость фотоэлектричества при его гибридном аккумулировании равна 3,1р., при электрохимическом $-3,5$ р. за кВт*ч.

5. Показана экономическая целесообразность распределённой фотоэлектрической генерации в условиях Ирака. Для рассмотренного примера срок окупаемости вложений в оборудование фотоэлектростанции равен 10-12 лет для вариантов с гибридной и электрохимической системами аккумулирования фотоэлектричества.

4. United Nations Framework Convention on Climate Change. URL: http://unfecc.int (дата обращения: 15.11.2020).

5. EIA's Annual Energy Outlook 2019 with projections to 2050. U.S. Energy Information Administration, 2019. URL: https://www.eia. gov/outlooks/aeo/pdf/aeo2019.pdf (дата обращения: 15.11.2020).

6. Lukutin B.V., Orazbekova A.K. Technical and economic feasibility of thermal accumulation of energy at autonomous photovoltaic power stations // International Eurasian Conference on future energy and IEEE international Siberian Conference on control and communications (SIBCON-2017). - Astana, Kazakhstan, 2017. DOI: https://ieeexplore.iee.org/document/7998489. 
7. Outdoor performance analysis of a photovoltaic thermal (PVT) collector with jet impingement and compound parabolic concentrator (CPC) / A.H. Jaaz, H.A. Hasan, K. Sopian, A.A.H. Kadhum, T.S. Gaaz, A.A. Al-Amiery // Materials. 2017. DOI: https://www.mdpi.com/1996-1944/10/8/888

8. Jaaz A.H., Sopian K., Gaaz T.S. Study of the electrical and thermal performances of photovoltaic thermal CollectorCompound parabolic concentrated // Results in Physics. - 2018. V. 9. - P. 500-510.

9. Bhowmik H., Amin R. Efficiency improvement of flat plate solar collector using reflector // Energy Reports. - 2017. - V. 3. P. 119-123.

10. Goswami D. Yogi. Advances in Solar Energy // An Annual Review of Research and Development in Renewable Energy Technology (Advances in Solar Energy Series). - 2007. - V. 17. P. 336.

11. Field study of the performance for a solar water heating system with MHPA-FPCs / H. Liu, W. Wang, Y. Zhao, Y. Deng // Energy Procedia. - 2015. - V. 70. - P. 79-86.

12. Analysis of the performance of a solar water heating system with flat collector / A.L.G. Vendramin, C.I. Yamamoto, C.E.C. Nogueira, A.M. Lenz, S.N.S. Melegari // World Academy of Sciences, Engineering and Technology. International Journal of Energy and Power Engineering. - 2015. - V. 9 (2) - - P. 386-389.

13. Лукутин Б.В., Муравьёв Д.И. Перспективы децентрализованных систем электроснабжения постоянного тока с распределённой солнечной генерацией // Известия Томского политехнического университета. Инжиниринг георесурсов. - 2020. T. 331. - № 6. URL: http://catalog.lib.tpu.ru/catalogue/simple/ document/RU/TPU/book/376831 (дата обращения: 15.11.2020).

14. Hauer A., Teuffel A. Integration of energy storage into energy systems // Handbook of Clean Energy Systems. 2015. DOI https://doi.org/10.1002/9781118991978.hces215.

15. Wang F., Zhu Y., Yan J. Performance of solar PV micro-grid systems: a comparison study // Energy Procedia. - 2018. - V. 45. P. $570-575$

16. Бутузов В.А. Солнечное теплоснабжение: статистика мирового рынка и особенности российского опыта // Теплоэнергетика. - 2018. - № 10. - С. 78-88.

\section{Информация об авторах}

Лукутин Б.В., доктор технических наук, профессор отделения электроэнергетики и электротехники Инженерной школы энергетики Национального исследовательского Томского политехнического университета.

Аль-Мажди Каррар Хамид, аспирант отделения электроэнергетики и электротехники Инженерной школы энергетики Национального исследовательского Томского политехнического университета.
17. Al-Nama M.A., Al-Hafid M.S., Al-Fahadi A.S. Estimation of the diversity factor for the Iraqi distribution system using intelligent methods // Al-Rafidain Engineering, Mosul. - 2009. - V. 17 (1). P. 14-21.

18. Al-Hafid M.S., Al-Nama M.A., Al-Fahadi A.S. Determination of residential electrical load components in Iraqi north region // Iraqi Journal for Electrical and Electronic Engineering, Basra, Iraq. - 2017. - V. 13 (2). - P. 161-165.

19. Milisic Edina. Modelling of energy storage using phase-change materials (PCM materials): Master's Thesis. 2013. URL: https://pdfs.semanticscholar.org/4053/e5b7e86be6c68a9848fc9b9c 5582af9c6616.pdf (дата обращения: 15.11.2020)

20. Ирак. Электроэнергетика // Polpred.com. Обзор СМИ-2020 (№ 3607553). DOI: polpred.com>news/?cnt=618/sector=19.

21. Shneishil A.H. Design and fabrication of evacuated tube solar thermal collector for domestic hot water // Journal of college education, Al-Mustansiriyah University, Iraq. - 2016. - № 3. P. 287-302.

22. NASA Surface Meteorology and Solar Energy. URL: www. instesre.com/Solar/grid.cgi.htm (дата обращения 16.11.2020).

23. СНиП 2.04.01-85 Нормы расхода воды потребителями. (Приложение 3). URL: www.stelmarket.ru>teh.inf/12-24.htm (дата обращения: 20.11.2020).

24. Ширко Д.И., Дорошевич В.И. Гигиенические требованию к водоснабжению военнослужащих. - Минск: БГМУ, 2015. $52 \mathrm{c}$.

25. On-line калькулятор солнечной, ветровой и тепловой энергии. URL: http://www.helios-house.ru/on-line-kalkulyator.html (дата обращения 25.11.2020).

26. Сравнение аккумуляторов: таблица типов - BEST ENERGY (2 марта 2016). URL: https://best-energy.com.ua/support/battery/bu107 (дата обращения: 25.11.2020).

27. Мировые тарифы: газ, бензин, и электроэнергия. URL: antoniomerloni.ru/world-gas-tariffs (дата обращения: 25.11.2020).

Поступила 23.12.2020 2. 
UDC 621.311 .002

\title{
PHOTOVOLTAIC POWER PLANTS WITH ELECTROCHEMICAL AND THERMAL ENERGY STORAGE IN IRAQ
}

\author{
Boris V. Lukutin', \\ lukutin48@mail.ru
}

\author{
Karrar Hameed Kadhim 1 , \\ karrar.almussawi.87@gmail.com \\ 1 National Research Tomsk Polytechnic University, \\ 30, Lenin avenue, Tomsk, 634050, Russia.
}

The relevance. One of the most environmentally friendly and reliable sources of natural energy is modern energy production technologies, especially renewable energy. This article introduces the concept of a hybrid solar storage system using a photovoltaic plant with electrochemical and thermal storage of electricity generated. For example, a region with a high level of solar radiation - Baghdad (Iraq). Studies were conducted for a model of social facility - a gym in Baghdad that needed electrical power and hot water supplies.

The main aim of the research is to study the possibility of reducing the cost of photovoltaic installation using solar electrochemical and thermal electricity batteries.

Objects: photovoltaic systems for social facilities with a large share of electrical heating loads in areas with a high level of solar radiation, for example, a gym in Baghdad (Iraq).

Methods: a combined method of accumulating solar energy: in electrochemical batteries and in thermal ones, methods of engineering sciences, modeling method.

Results. The technical and economic efficiency of the local power supply system with a high percentage of thermal loads was analyzed taking into account the instability of solar radiation during the seasons of the year, temperatures, and energy consumption tables. The economic efficiency of the electrochemical battery of a photoelectric plant with a solar water heater collector was compared.

\section{Key words:}

Renewable energy, solar radiation, photovoltaic power plant, electrochemical and electrothermal energy storage, simulation solar systems.

\section{REFERENCES}

1. BP Statistical review of world energy. 2018. Available at: https://bp.com/content/dam/bp/business-sites/en/global/corporate/ pdfs/energy-economics/statistical-review/bp-stats-review-2018full-report.pdf (accessed 15 November 2020).

2. Sawe Y., Gopta S.C., Bohra A.V. Review of hybrid renewable energy systems with comparative analysis of off-grid system. $R e$ newable and Sustainable Energy Reviews, 2018, vol. 81 (2), pp. 2217-2235.

3. Key world energy statistics. International Energy Agency. 2010. Available at: http://www.iea.org (accessed 15 November 2020).

4. United Nations Framework Convention on Climate Change. Available at: http://unfccc.int (accessed 15 November 2020).

5. EIA's Annual Energy Outlook 2019 with projections to 2050. U.S Energy Information Administration, 2019. Available at: https://www. eia.gov/outlooks/aeo/pdf/aeo2019.pdf (accessed 15 November 2020)

6. Lukutin B.V., Orazbekova A.K. Technical and economic feasibility of thermal accumulation of energy at autonomous photovoltaic power stations. International Eurasian Conference on future energy and IEEE international Siberian Conference on control and communications (SIBCON-2017). Astana, Kazakhstan, 2017. DOI: https://ieeexplore.ieee.org/document/7998489.

7. Jaaz A.H., Hasan H.A., Sopian K., Kadhum A.A.H., Gaaz T.S., Al-Amiery A.A. Outdoor performance analysis of a photovoltaic thermal (PVT) collector with jet impingement and compound parabolic concentrator (CPC). Materials. 2017. DOI: https://www.mdpi.com/1996-1944/10/8/888.

8. Jaaz A.H., Sopian K., Gaaz T.S. Study of the electrical and thermal performances of photovoltaic thermal Collector-Compound parabolic concentrated. Results in Physics, 2018, vol. 9, pp. 500-510.

9. Bhowmik H., Amin R. Efficiency improvement of flat plate solar collector using reflector. Energy Reports, 2017, vol. 3, pp. 119-123.

10. Goswami D. Yogi. Advances in Solar Energy. An Annual Review of Research and Development in Renewable Energy Technology (Advances in Solar Energy Series), 2007, vol. 17, 336 p.

11. Liu H., Wang W., Zhao Y., Deng Y. Field study of the performance for a solar water heating system with MHPA-FPCs. Energy Procedia, 2015, vol. 70, pp. 79-86.
12. Vendramin A.L.G., Yamamoto C.I., Nogueira C.E.C., Lenz A.M., Melegari S.N.S. Analysis of the performance of a solar water heating system with flat collector. International Journal of Energy and Power Engineering, 2015, vol. 9 (2), pp. 386-389.

13. Lukutin B.V., Muravyov D.I. Prospects for decentralized DC power supply systems with distributed solar generation. Bulletin of the Tomsk Polytechnic University. Geo Assets Engineering, 2020, vol. 331, no. 6. In Rus. Available at: http://catalog.lib.tpu.ru/ catalogue/simple/document/RU/TPU/book/376831 (accessed 15 November 2020).

14. Hauer A., Teuffel A. Integration of energy storage into energy systems. Handbook of Clean Energy Systems. 2015. DOI: https://doi.org/10.1002/9781118991978.hces215.

15. Wang F., Zhu Y., Yan J. Performance of solar PV micro-grid systems: a comparison study. Energy Procedia, 2018, vol. 45, pp. $570-575$.

16. Butuzov V.A. Solar heat supply: statistics of the world market and features of the Russian experience. Teploenergetika, 2018, no. 10, pp. 78-88. In Rus.

17. Al-Nama M.A., Al-Hafid M.S., Al-Fahadi A.S. Estimation of the diversity factor for the Iraqi distribution system using intelligent methods. Al-Rafidain Engineering, Mosul, 2009, vol. 17 (1), pp. 14-21.

18. Al-Hafid M.S., Al-Nama M.A., Al-Fahadi A.S. Determination of residential electrical load components in Iraqi north region. Iraqi Journal for Electrical and Electronic Engineering, Basra, Iraq, 2017, vol. 13 (2), pp. 161-165.

19. Milisic Edina. Modelling of energy storage using phase-change materials (PCM materials). Master's Thesis. 2013. Available at: https://pdfs.semanticscholar.org/4053/e5b7e86be6c68a9848fc9b9c 5582af9c6616.pdf (accessed: 15 November 2020).

20. Iraq. Power engineering. Polpred.com. № 3607553. DOI: polpred.com $>$ news/?cnt $=618 /$ sector $=19$

21. Shneishil A.H. Design and fabrication of evacuated tube solar thermal collector for domestic hot water. Journal of college education, Al-Mustansiriyah University, Iraq, 2016, no. 3, pp. 287-302.

22. NASA Surface Meteorology and Solar Energy. Available at: www.instesre.com/Solar/grid.cgi.htm (accessed 16 November 2020). 
23. SNiP 2.04.01-85: Normy raskhoda vody potrebitelyami [Water consumption rates by consumers]. Available at: http://www. stelmarket.ru>teh.inf (accessed 20 November 2020).

24. Shirko D.I., Doroshevich V.I. Gigienicheskie trebovaniya $k$ vodosnabzheniyu voennosluzhashikh [Hygienic requirements for water supply for military personnel]. Minsk, BSMU Publ., 2015. $52 \mathrm{p}$.

25. On-line calculator of solar, wind and thermal energy. Available at: http://www.helios-house.ru/on-line-kalkulyator.html (accessed 25 November 2020).

\section{Information about the authors}

Boris V. Lukutin, Dr. Sc., professor, National Research Tomsk Polytechnic University.

Karrar Hameed Kadhim, postgraduate student, National Research Tomsk Polytechnic University.
26. Comparison of batteries: table of types - BEST ENERGY. Available at: https://best-energy.com.ua/support/battery/bu-107 (accessed 25 November 2020)

27. World Tariffs: Gas, Gasoline, and Electricity. Available at: antonio-merloni.ru/world-gas-tariffs (accessed 25 November 2020).

Received: 23 December 2020. 